\title{
PELATIHAN DAN PENDAMPINGAN MERANCANG INSTRUMEN ASSESSMENT FOR LEARNING BERBASIS PORTOFOLIO PADA GURU-GURU SEKOLAH
}

\author{
Jenny Indrastoeti Siti Poerwanti ${ }^{1}$, Retno Winarni ${ }^{2}$ \\ ${ }^{1,2}$ PGSD FKIP, Universitas Sebelas Maret \\ e-mail: jenny_isp@staff.uns.ac.id, retnowinarni@staff.uns.ac.id
}

\begin{abstract}
Abstrak
Kegiatan pengabdian ini bertujuan untuk memberikan pelatihan dan meningkatkan kompetensi guru dalam merancang dan menyusun instrumen assessment for learning berbasis portofolio yang dilengkapi dengan rubric penilaian bagi guru-guru SD di kecamatan Laweyan Surakarta. Hal ini didasarkan pada hasil need assesment yang telah dilaksanakan di awal kegiatan, bahwa sebagian guru masih kesulitan dalam menyusun rubrik ketika merancang dan menyusun instrumen penilaian. Kegiatan pelatihan dilaksanakan dalam tiga tahapan yaitu: 1). pemaparan materi asesmen, 2) pelatihan menyusun instrumen penilaian berbasis porofolio, 3) pendampingan dalam mengimplementasikan instrumen penilaian portofolio dalam kelas, 4) Evaluasi kegiatan. Metode yang digunakan adalah ceramah dan pelatihan partisipatif, serta pemberian tugas.Subjek yang dilibatkan sebanyak 20 guru SD di Kecamatan Laweyan Kota Surakarta. Pengumpulan data yang digunakan adalah pemberian tugas merancang instrumen penilaian portofolio dilengkapi dengan rubrik, kemudian dianalisis menggunakan analisis deskriptif. Hasil pengabdian menunjukkan respon positif guru dalam mengikuti kegiatan pelatihan dan meningkatnya kompetensi guru dalam menyusun assessment for learning berbasis portofolio.
\end{abstract}

Kata kunci: assessment for learning, penilaian portofolio, guru sekolah dasar

\begin{abstract}
This service activity aims to provide training and improve teacher competence in designing and compiling a portfolio-based assessment for learning instrument equipped with an assessment rubric for elementary school teachers in Laweyan Surakarta district. This is based on the results of the need assessment that was carried out at the beginning of the activity, that some teachers still have difficulty compiling rubrics when designing and compiling assessment instruments. Training activities are carried out in three stages, namely: 1). presentation of the assessment material, 2) training to prepare a portfolio-based assessment instrument, 3) assistance in implementing portfolio assessment instruments in class, 4) Evaluation of activities. The method used was lectures and participatory training, as well as assignments. The subjects involved were 20 elementary school teachers in Laweyan District, Surakarta City. The data collection used was the assignment of designing a portfolio assessment instrument equipped with a rubric, then analyzed using descriptive analysis. The service results show a positive response from teachers in participating in training activities and an increase in teacher competence in preparing a portfolio-based assessment for learning. This can be seen from the percentage of trainee attendance at $90 \%$, and $82 . \%$ of the total participants have succeeded in compiling and presenting the portfolio assessment instrument.
\end{abstract}

Keywords : assessment for learning, portfolio assessment, elementary school teachers

\section{PENDAHULUAN}

Suatu proses pembelajaran dapat berjalan dengan baik atau tidak, dapat dilihat dari tercapai atau tidaknya tujuan pembelajaran yang ditetapkan. Keberhasilan tersebut hanya dapat 
diketahui jika guru mengadakan penilaian/asesmen terhadap hasil belajar peserta didik. Salah satu karakteristik penilaian kelas dalam Kurikulum 2013 adalah penilaian autentik. Penilaian autentik merupakan penilaian yang dilakukan secara komprehensif untuk menilai aspek kognitif, keterampilan, dan sikap. Penilaian yang selama ini masih banyak dilakukan oleh guru di Sekolah dasar adalah penilaian dengan tes baku yang berbentuk tes objektif. Tes baku tidak mampu menampilkan kemampuann siswa secara menyeluruh.

Kegiatan proses asesmen/penilaian bukan semata- mata asesmen belajar (assessment of learning) tetapi asesmen untuk pembelajaran (assessment for learning).Penilaian/asesmen tidak lagi dilihat semata-mata sebagai proses pengukuran pencapaian kemampuan peserta didik selama dan di akhir program, tetapi harus dimanfaatkan sebagai umpan balik (feed back), untuk memperbaiki proses pembelajaran, baik oleh peserta didik maupun pendidik. Penggunaan feed back dalam pembelajaran, sebagai umpan balik yang direfleksikan oleh peserta didik untuk mengetahui seberapa jauh kemampuannya dalam memahami pembelajaran (Basuki \& Hariyanto,2014). Feed back pada assessment for learning merupakan alat yang dipergunakan peserta didik untuk merefleksikan dan memaknai konsep pembelajaran sehingga peserta didik memperoleh pengetahuan yang benar (Chng, 2018; Shute et al., 2017). Hal ini sesuai dengan pendapat Sudiyanto dkk: 2015 menyatakan bahwa asesmen dapat digunakan: (1) untuk menentukan tingkat pencapaian hasil pembelajaran (2) untuk memperbaiki proses pembelajaran oleh guru dan (3) untuk memperbaiki proses pembelajaran oleh siswa. Dalam kaitannya dengan penggunaan assessment for learning telah dilakukan review literature oleh (Black dan William, 1988) dalam (Sudiyono; 2014) yang menyimpulkan bahwa penggunaan assessment for learning yang dirancang dengan baik dan benar dapat meningkatkan kompetensi peserta didik.

Salah satu bentuk assessment for learning yang dapat memberikan umpan balik bagi kemajuan peserta didik adalah asesmen/penilaian portofolio. Penilaian portofolio digunakan karena portofolio bisa mengungkapkan dan mendokumentasikan hasil belajar peserta didik dalam kegiatan yang berbeda-beda dan dalam kurun waktu yang ditentukan (Waseso, Amiri \& Tatminingsih, 2011). Cara ini banyak memberikan masukan dalam asesmen, dan mudah dimengerti orang tua, serta mendorong evaluasi diri peserta didik itu sendiri. Isi portofolio merupakan bukti proses dan hasil kegiatan nyata peserta didik didik, dan oleh guru dapat dijadikan dasar pengambilan keputusan. Menurut (Sunarti dan Rahmawati, 2014) penggunaan penilaian portofolio dalam pembelajaran mempersyaratkan keterlibatan peserta didik secara aktif.

Penilaian portofolio merupakan penilaian berkelanjutan yang didasarkan pada kumpulan hasil karya yang menunjukkan perkembangan kemampuan peserta didik dalam satu periode tertentu. Hasil karya siswa bisa berupa hasil ulangan dari proses pembelajaran yang dianggap terbaik oleh peserta didik, atau hasil karya berupa menggambar suatu objek tertentu.. Penilaian portofolio memiliki beberapa kelebihan. Portofolio lebih obyektif memotret hasil karya peserta didik yang sebenarnya dan portofolio juga lebih terbuka karena peserta didik ikut serta menilai pekerjaan yang dilakukannya. (Agusditya et al., 2017; Brown et al., 2017; Kusaeri, 2014)

Menurut Adisusila (2014:249) "portofolio merupakan kumpulan hasil karya siswa yang didokumentasikan secara baik dan teratur. Karya siswa ini dapat berupa kliping, tugas individual, hasil wawancara dan lain-lain". Dengan demikian, Portofolio dijadikan dasar untuk melihat dan menilai proses perkembangan pengetahuan, keterampilan, dan sikap dari peserta didik, menjadi bukti tentang apa yang dapat dilakukan oleh peserta didik selama pembelajaran. Penilaian portofolio bertujuan untuk merefleksi suatu pekerjaan yang telah di kerjakan oleh peserta didik (Efendi et al., 2017; Kuntarto \& Gustina, 2019).

Kendala dalam menyusun instrumen penilaian portofolio sangat dirasakan oleh 
guru-guru SD di kecamatan Laweyan. Hal ini sebagai temuan dari need asesmen yang telah dilakukan pada kegiatan pelatihan terdahulu yang telah dilaksanakan (Poerwanti, dkk 2018) dengan judul pelatihan penilaian proses dan hasil belajar berdasarkan kurikulum 2013. Disamping itu kegiatan serupa juga telah dilakukan berkaitan dengan pelatihan asesmen high order thinking skill pada guru-guru SD.(Poerwanti,2020).Penelitian yang berkaitan dengan asesmen juga telah dilakukan pada thn 2017 dengan judul "Asesmen Authentik dalam pembelajaran bahasa Indonesia. Dari penelitian tersebut ditemukan bahwa sebagian guru memang masih kesulitan dalam menyusun instrumen penilaian baik instrumen tes maupun nontes. Berdasarkan hasil wawancara dengan guru-guru SD di kecamatan Laweyan, hanya ada dua guru yang sudah pernah mengikuti pelatihan tentang asesmen/penilaian hasil belajar.

Berdasarkan pengamatan di lapangan dan dari hasil observasi peneliti di SD yang digunakan PPL (Praktik Pengalaman Lapangan), guru masih cenderung menggunakan model tes. baik dalam menilai proses dan hasil pembelajaran, tanpa menghiraukan apakah itu mengukur aspek kognitif, afektif, maupun psikomotor. Dalam hal mengukur keterampilan menulis peserta didik tidak jarang tanpa disertai rubrik penilaian dan terkesan kurang perencanaan yang matang. Masalah tersebut diupayakan solusinya melalui program pengabdian masyarakat berupa memberikan pelatihan penyusunan instrumen assessment for learning berbasis portofolio di kecamatan Laweyan.

\section{METODE \\ Khalayak Sasaran}

Sasaran dari kegiatan pengabdian ini adalah guru di kecamatan Laweyan yang berjumlah 20 guru. Adapun alur kegiatan pengabdian ini adalah sebagai berikut.

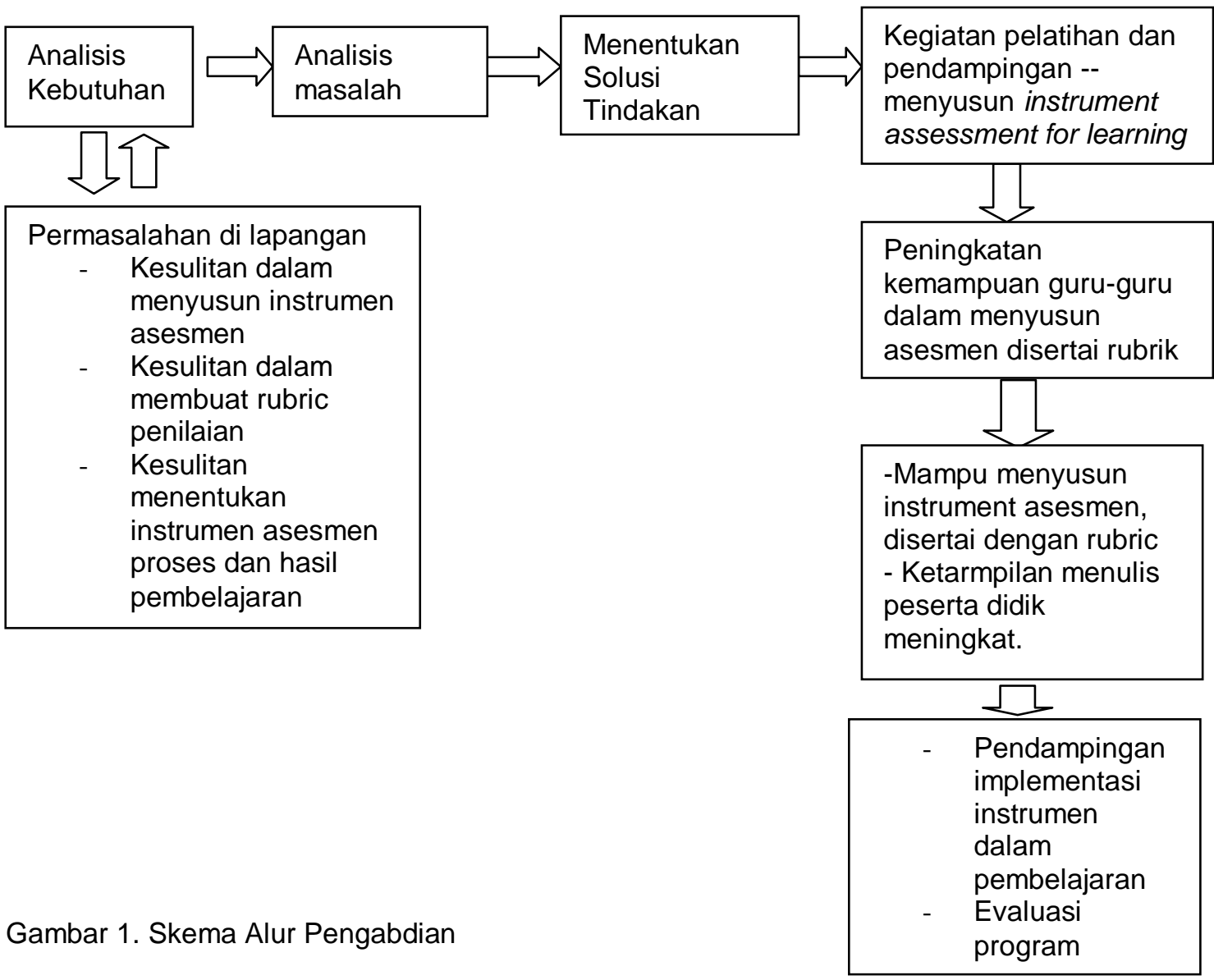


Keberhasilan pelaksanaan pelatihan ini dilihat dari: 1) kehadiran peserta pelatihan yang dilihat pada daftar presensi peserta, minimal peserta yang hadir mencapai $75 \%$ dari total undangan peserta latihan, 2) partisipasi peserta latihan dalam mengikuti kegiatan selama pelatihan berlangsung, 3) kemampuan mempresentasikan hasil instrumen yang disusun, 4) Kelengkapan instrumen yang disusun.

\section{Metode Pelaksanaan Kegiatan}

Secara garis besar pemecahan masalah dilakukan dengan melakukan analisis kebutuhan guru di kecamatan laweyan mengenai kesulitan dalam merancang instrumen khususnya instrumen assessment for learning berbasis portofolio. Dari hasil analisis kebutuhan tersebut dilakukan analisis masalah dan dilanjutkan dengan melaksanakan tindakan perbaikan melalui pelatihan dan pendampingan, serta melakukan evaluasi terhadap program kegiatan latihan tersebut. Jika dijabarkan kegiatan pelatihan ini dibagi menjadi tiga tahap kegiatan yaitu: Perencanaan yang diawali dengan koordinasi antar tim dengan kepala sekolah, kemudian melaksanakan tindakan yang terdiri dari kegiatan pemaparan materi awal, pelatihan menyusun dan pendampingan serta yang terakhir melaksanakan evaluasi kegiatan. Tahapan ini dapat digambarkan sebagai berikut.

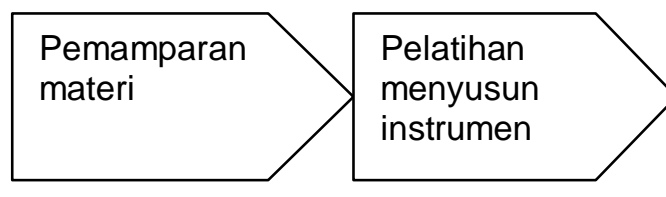

Gambar 2. Kegiatan Pelatihan

Metode akan memaparkan secara rinci tentang jenis/ rancangan pengabdian masyarakat yang dilaksanakan, metode serta langkah -langkah pelaksanaan sampai dengan evaluasi serta monitoring pelaksanaan pengabdian.

\section{HASIL DAN PEMBAHASAN}

Hasil yang diperoleh dari kegiatan ini cukup berhasil, penggunaan pendekatan kolaboratif dengan metode ceramah, diskusi, pemberian tugas dan praktik langsung ternyata dapat meningkatkan pengetahuan dan kemampuan guru dalam merancang instrumen penilaian berbasis portofolio. Pada tahap pelaksanaan metode pemberian tugas, masing-masing kelompok membuat instrumen penilaian portofolio. Hasil dari masing-masing kelompok dipresentasikan untuk dianalisis dan diberi umpan balik dalam rangka penyempurnaan instrumen. Sehingga dari contoh-contoh yang dihasilkan dapat dijadikan pedoman untuk merancang instrumen penilaian portofolio. Adapun hasil dari pelaksanaan P2M ini adalah sebagai berikut.

a. Kehadiran peserta dalam mengikuti pelatihan penyusunan instrumen

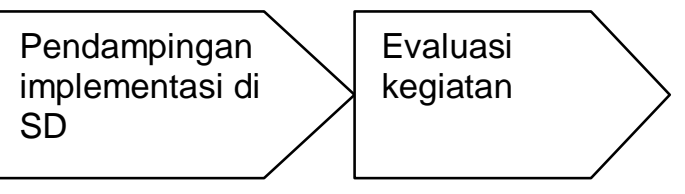

assessment for learning telah mencapai $90 \%$

b. Partisipasi kerjasama peserta latihan dalam mengikuti kegiatan selama pelatihan berlangsung secara keseluruhan $71,4 \%$ Pembagian tugas dalam kelompok cukup baik dan lancar, masing-masing kelompok interaktif dan berani mengemukakan pendapat serta bertanya

c. Kemampuan mempersentasikan instrumen yang disusun dalam kelompok baik

d. Kelengkapan komponen portofolio yang disusun sudah baik, dengan dilengkapi rubrik penilaian.

Dari hasil postes yang diadakan setelah akhir dari kegiatan P2M sebagian peserta sudah mampu menyusun instrumen assessment for learning berbasis portofolio didasarkan pada kompensi yang akan diukur yang juga disertai dengan rubrik penilaian. Adapun data-data dari hasil kegiatan di atas dapat dilihat pada tabel di bawah ini. 
Tabel 1. Data Partisipasi Peserta Pada Diskusi Kelompok

\begin{tabular}{clcc}
\hline No & Aktivitas & $\begin{array}{c}\text { Jumlah } \\
\text { Peserta }\end{array}$ & Persentase \\
\hline 1 & Kehadiran & 20 & $90 \%$ \\
2 & Mendengarkan & 19 & $85 \%$ \\
3 & Mengerjakan tugastugas & 17 & $78 \%$ \\
4 & Mengajukan pertanyaan & 16 & $72 \%$ \\
5 & Menjawab pertanyaan & 9 & $16 \%$ \\
6 & Mengemukakan pendapat & 15 & $70 \%$ \\
7 & Presentasi & 18 & $82 \%$ \\
8 & Bekerjasama & 17 & $78 \%$ \\
\hline
\end{tabular}

Tabel 2. Data Kemampuan Presentasi Merancang Instrumen Portofolio

\begin{tabular}{|c|c|c|c|c|c|}
\hline No & Indikator & Kurang & Cukup & Baik & $\begin{array}{c}\text { Sangat } \\
\text { Baik }\end{array}$ \\
\hline 1 & Penyajian & & & V & \\
\hline 2 & Tata letak/display & & & V & \\
\hline 3 & Sistematika bahasa & & & & $\mathrm{V}$ \\
\hline 4 & Sikap presentasi & & & & $\mathrm{V}$ \\
\hline 5 & $\begin{array}{ll}\text { Kesesuaian } & \text { Instrumen } \\
\text { dengan indikator }\end{array}$ & & & V & \\
\hline 6 & $\begin{array}{l}\text { Ketepatan Instrumen dengan } \\
\text { teknik penilaian }\end{array}$ & & & V & \\
\hline 7 & Kelengkapan instrumen & & & & $\mathrm{V}$ \\
\hline 8 & Variasi instrumen & & & $\mathrm{V}$ & \\
\hline
\end{tabular}

Tabel 3. Data Kelengkapan Komponen Instrumen Portofolio

\begin{tabular}{|c|c|c|c|c|c|}
\hline No & Indikator & Kurang & Cukup & Baik & $\begin{array}{c}\text { Sangat } \\
\text { Baik }\end{array}$ \\
\hline 1 & $\begin{array}{lll}\begin{array}{l}\text { Menentukan } \\
\text { portofolio }\end{array} & \text { Fokus isi } \\
\end{array}$ & & & $\mathrm{V}$ & \\
\hline 2 & $\begin{array}{l}\text { Menentukan } \\
\text { Bentuk/susunan portofolio }\end{array}$ & & V & & \\
\hline 3 & $\begin{array}{l}\text { Menentukan penggunaan } \\
\text { portofolio }\end{array}$ & & & V & \\
\hline 4 & $\begin{array}{l}\text { Menentukan cara penilaian } \\
\text { portofolio }\end{array}$ & & & V & \\
\hline 5 & $\begin{array}{l}\text { Dilengkapi dengan rubrik } \\
\text { penilaian }\end{array}$ & & & V & \\
\hline
\end{tabular}

Secara keseluruhan hasil kegiatan pelatihan ini sudah dapat dikatakan berhasil dan memberi manfaat bagi para guru-guru SD dalam menambah pengetahuan dan teknologi. Hal ini juga berkontribusi pada keefektifan proses pembelajaran di sekolah dasar. Mengingat kemampuan guru dalam menyusun instrumen dan melaksanakan proses penilaian sangat penting, karena melalui proses penilaian yang tepat akan dapat memantau perkembangan peserta didik, melalui pemberian umpan balik bagi pendidik/siswa untuk menyempurnakan perencanaan proses dan proses pembelajaran (Kemendikbud, 2014).

Hasil kegiatan PPM secara garis besar mencakup beberapa komponen sebagai berikut: a) Keberhasilan target jumlah peserta pelatihan, b) Ketercapaian tujuan pelatihan, c) Ketercapaian target 
materi yang telah direncanakan, d) Kemampuan peserta dalam menyusun instrumen portofolio.

Target pelatihan seperti direncanakan sebelumnya adalah 22 peserta namun yang hadir sampai selesai kegiatan pelatihan berjumlah 20 peserta yang terdiri 1 kepala sekolah dan 19 guru. Sehingga dalam pelaksanaannya kegiatan ini diikuti 20 peserta. Dengan demikian dapat dikatakan bahwa target peserta telah tercapai. Ketercapaian tujuan pelatihan dan pendampingan tentang merancang instrumen penilaian portofolio secara umum sudah baik, namun keterbatasan waktu yang disediakan mengakibatkan tidak semua materi dapat disampaikan secara detil, khususnya contoh-contoh dan presentasi tugas individu. Namun dilihat dari hasil latihan para peserta yaitu kualitas hasil instrumen pembelajaran yang telah dihasilkan, maka dapat disimpulkan bahwa tujuan kegiatan ini dapat tercapai.

Kemampuan peserta dilihat dari penguasaan materi tentang asessmen masih belum maksimal dikarenakan waktu yang singkat dalam penyampaian materi dan kemampuan para peserta yang berbeda-beda. Namun hal ini dapat diatasi dengan pembentukan kelompok sehingga masing-masing anggota kelompok dapat berinteraksi saling membantu dan mendukung dalam hal menyelesaikan tugas yang diberikan.

Secara keseluruhan kegiatan pelatihan dan pendampingan pada penyusunan dan merancang instrumen penilaian portofolio dapat memberikan pengetahuan dan wawasan guru dalam melaksanakan penilaian di sekolah dasar. Keberhasilan ini selain diukur dari keempat komponen di atas, juga dapat lihat dari kepuasan peserta setelah mengikuti kegiatan.

Jika dilihat dari hasil aktivitas peserta dalam diskusi kelompok menyusun instrumen portofolio, keaktifan peserta sudah sangat baik, $78 \%$ peserta aktif bekerja sama dalam diskusi. Dari unsur keantusiasan mendengarkan materi yang disampaikan $85 \%$ siswa aktif mendengarkan narasumber, keaktifan mengerjakan tugas2 yang diberikan $78 \%$ peserta latihan menyelesaikan tugas-tugas yang diberikan. Kemampuan peserta dalam merancang dan menyusun instrumen juga sudah sangat baik, hal ini dapat dilihat ketika peserta mempresentasikan hasil diskusi kelompok. Hal ini dapat dilihat dari kesesuaian instrumen dengan indikator penilaian, kelengkapan instrumen, dan ketepatan instrumen yang digunakan.. Dari hasil yang telah dicapai dari kegiatan pelatihan dan pendampingan ini dapat dikatakan bahwa melalui metode pelatihan akan dapat meningkatkan kinerja guru dalam menyusun maupun merancang instrumen penilaian portofolio, sebagai mana yang dinyatakan oleh Rivai dan sagala, 2012, bahwa pelatihan sebagai bagian pendidikan dalam waktu relatif singkat untuk meningkatkan kinerja serta mengutamakan praktek dari pada teori. Sedangkan menurut Simamora dalam Kamil (2010), pelatihan merupakan serangkaian aktivitas yang dirancang untuk meningkatkan pengetahuan, keahlian, maupun pengalaman, agar individu dapat mengubah sikapnya. Dalam hal ini manfaat yang diperoleh guru adalah dapat menyusun dan mengembangkan instrumen penilaian yang lebih baik dan diharapkan kualitas tersebut diikuti dengan penerapan pelaksanaan penilaian dalam proses pembelajaran di sekolah dasar.

Keberhasilan dari pelatihan ini antara lain disebabkan karena pelatihan yang terkait dengan penyusunan instrumen penilaian khususnya assessment for learning (AfL) masih sangat jarang dilaksakan, sehingga berdampak pada keantusiasan guru untuk mengikuti pelatihan ini. Hal lain juga karena metode pelatihan yang dilaksankan disertai pendampingan pada guru-guru dalam mempraktekkan instrumen yang telah dirancang dan disusun.

Keberlanjutan yang diharapkan dari pengabdian ini merujuk pada konsistensi guru dalam melaksanakan AfL berbasis portofolio di sekolah dasar. Penelitian terdahulu menunjukkan efektivitas penerapan AfL untuk meningkatkan motivasi dan hasil belajar siswa (Baas et I., 2018; Payne et al., 2020; Yusron \& Sudiyatno, 2020). Kunci dari pelaksanaan tidak hanya terletak pada kemampuan penyusunan dan penerapan AfL, melainkan 
juga terletak pada kemauan guru (Lysaght et al., 2017; Hongying et al., 2017). Pelatihan ini berupaya agar para guru mampu dan mau menerapkan AfL yang dilaksanakan berbasis portofolio. Penerapan AfL dengan berbasis pada portofolio ini dapat meningkatkan efektivitas dalam fungsi penilaian sebagai peningkatan proses dan hasil belajar pembelajaran (Barton \& Collins, 1997; Maharani et al., 2020; Mak \& Wong, 2018; Saeed et al., 2018).

\section{KESIMPULAN}

Pelaksanaan kegiatan pelatihan pengabdian pada masyarakat yang berjudul "Pelatihan dan Pendampingan Merancang Instrumen Assessment for Learning Berbasis Portofolio Pada Guru Sekolah Dasar" telah mampu mengatasi permasalahan yang dihadapi oleh guru. Hal ini terlihat dari partisipasi guru dalam mengikuti kegiatan dan meningkatnya kompetensi guru dalam menyusun instrumen assessment for learning berbasis portofolio. Hasil dari kegiatan ini dapat dijadikan acuan untuk melaksanakan pelatihan kegitan yang berkaitan dengan penilaian di sekolah dasar untuk menungkatkan kompetensi guru dalam melaksanakan penilaian di SD. Hasil kegiatan ini perlu dilakukan secara berkelanjutan sehingga dapat memberikan dampak positip bagi peningkatan kualitas kompetensi guru dan kualitas proses pembelajaran di SD. Waktu pelaksanaan kegiatan pengabdian perlu ditambah agar tujuan kegiatan dapat tercapai sepenuhnya, tetapi dengan konsekuensi penambahan biaya pelaksanaan.

\section{DAFTAR PUSTAKA}

Abidin, Y. (2012). Model penilaian otentik Dalam pembelajaran membaca pemahaman Beroreintasi pendidikan karakter. Jurnal Pendidikan Karakter.

Adisusila. (2014). Pembelajaran Nilai Karakter VCT Sebagai Inovasi Pendekatan Pembelajaran Afektif. Jakarta: Rajawali

Agusditya, P. H., Asri, I. S., \& Suara, I. M. (2017). The Effect of Scientific Approach Based on Portfolio
Assessment towards the Learning Outcomes of Civic Education of the Students Grade V Viewed from the Tendency of Observing Objects on Theme 7 SDN 4 Ubung. Journal of Education Research and Evaluation, 1(2), 91-99.

Baas, D., Vermeulen, M., Castelijns, J., Martens, R., \& Segers, M. (2020). Portfolios as a tool for AfL and student motivation: are they related?. Assessment in Education: Principles, Policy \& Practice, 27(4), 444-462.

Barton, J., \& Collins, A. (1997). Portfolio Assessment: A Handbook for Educators. Assessment Bookshelf Series. Dale Seymour Publications.

Basuki, Ismet \& Hariyanto.( 2014). Asesmen Pembelajaran. Bandung: PT Remaja Rosdakarya.

Brown, C. L., Park, Y., Schell, R., \& Benedict, A. E. (2017). Portfolio assessment for English learners: A magnifier into students' learning needs in literacy. New England Reading Association Journal, 52(1), 81-121.

Chng, L. S., \& Lund, J. (2018). Assessment for learning in physical education: The what, why and how. Journal of Physical Education, Recreation \& Dance, 89(8), 29-34.

Efendi, Z., Usman, B., \& Muslem, A. (2017). Implementation of portfolio assessment in teaching English writing. English Education Journal, 8(2), 187-198.

Hongying, X. (2017). The Model Construction and Application of AFL Composition Teaching in the Elementary School Based on the Key Competencies. Educational Measurement and Evaluation, (1), 3.

Jurnal Penelitian dan Evaluasi Pendidikan Volume 19, No 2, Desember 2015 (189-201) Online: http://journal.uny.ac.id/index.php/jpe $\mathrm{p}$

Kamil, M. 2010. Model Pendidikan dan Pelatihan. Bandung: Alfabeta.

Kemendikbud. (2014) Penilaian Pencapaian Kompetensi Pesrta Didik Sekolah Menengah Pertama. 
Kuntarto, E., \& Gustina, R. (2019). Pelaksanaan Penilaian Portofolio Di Sekolah Dasar. Jurnal Gentala Pendidikan Dasar, 4(2), 190-200.

Kusaeri. (2014). Penilaian dan Teknik Penilaian Proses dan Hasil Belajar dalam Kurikulum 2013. Yogyakarta: Ar. Ruzz Media.

Lysaght, Z., O'Leary, M., \& Ludlow, L. (2017). Measuring Teachers' Assessment for Learning (AfL) Classroom Practices in Elementary Schools. International Journal of Educational Methodology, 3(2), 103115.

Maharani, E., Suntoro, I., \& Ambarita, A. (2020). Development of Portfolio Assessment Instrument Based On Writing Works to Measur Communication Capabilities Students in Class V Elementary School. IOSR Journal of Research \& Method in Education (IOSR-JRME), 10(1), 52-59.

Mak, P., \& Wong, K. M. (2018). Selfregulation through portfolio assessment in writing classrooms. Elt Journal, 72(1), 49-61.

Paryanto \& Sudiyatno. (2011). Implementasi model assessment for learning (AFL) pada pembelajaran proses pemesinan di jurusan pendidikan teknik mesin FT UNY. JPTK Vol.20 No.1 Mei 2011.

Payne, E. M., Hodges, R., \& Hernandez, E. P. (2017). Changing Demographics and Needs Assessment for Learning Centers in the 21st Century. Learning Assistance Review, 22(1), 21-36.
Putra, Sitiatava Rizema. 2013. Desain Evaluasi Belajar Berbasis Kinerja. Jogjakarta: Diva Press.

Rivai, Veithzal \& Jauvani Sagala. 2011. Manajemen Sumber Daya Manusia untuk Perusahaan Dari Teori ke Praktik. Jakarta: Rajawali Press.

Resmini, Novi. (2010). Penilaian dalam Pembelajaran Bahasa Indonesia. Universitas Pendidikan Indonesia. (Online)

http://www.Penilaian_dalam_pengaj aran bahasa.

Saeed, M., Tahir, H., \& Latif, I. (2018). Teachers' Perceptions about the Use of Classroom Assessment Techniques in Elementary and Secondary Schools. Bulletin of Education and Research, 40(1), 115-130.

Shute, V. J., \& Rahimi, S. (2017). Review of computer-based assessment for learning in elementary and secondary education. Journal of Computer Assisted Learning, 33(1), 1-19.

Supranata, S dan Sumarna, 2004. Analisis Validitas, Reliabilitas dan Interpretasi hasil Tes Implementasi Kurikulum. Bandung: PT Remaja Rosdakarya.

Waseso, I., Amiri, M., \& Tatminingsih, S. (2011). Evaluasi Pembelajaran TK. Jakarta: Universitas Terbuka.

Yusron, E., \& Sudiyatno, S. (2020). How is the impact of Assessment for Learning (AfL) on mathematics learning in elementary schools? Jurnal Prima Edukasia, 9(1). 